\title{
Psykisk ohälsa, självmordstankar och självmordsförsök bland homosexuella, bisexuella och transpersoner (hbt) - resultat från två svenska undersökningar
}

\author{
Av Regina Winzer och Gunnel Boström
}

\begin{abstract}
Homosexuella, bisexuella och transpersoners hälsa har analyserats i en nationell befolkningsundersökning och i en riktad internetundersökning. Båda studierna visar på stora andelar av såväl psykisk ohälsa som utsatthet i olika former. Förslag till förebyggande insatser, framför allt på samhällelig nivå, är angelägna och har överlämnats till regeringen.
\end{abstract}

\section{Bakgrund}

Trots att majoriteten av homosexuella, bisexuella och transpersoner uppger att de har ett gott allmänt hälsotillstånd, visar flera internationella undersökningar att både den allmänna och den psykiska hälsan är sämre bland homo- och bisexuella kvinnor och män jämfört med heterosexuella (Bailey, 1999; Cochran, Mays, \& Sullivan, 2003; Meyer, 2003; Sandfort, de Graaf, Bijl, \& Schnabel, 2001). Även NOVA-studien har kommit till detta resultat (Hegna, Kristiansen, \& Moseng, 1999).

Statens folkhälsoinstitut (FHI) arbetar med att följa upp folkhälsan i Sverige. Det övergripande målet är att skapa samhälleliga förutsättningar för en god hälsa på lika villkor för hela befolkningen.

I november 2003 fick FHI regeringens uppdrag att undersöka och analysera hälsosituationen för homosexuella, bisexuella och transpersoner (hbt), då denna tidigare inte undersökts.

\section{Undersökningarna}

Sedan år 2004 genomför FHI tillsammans med Statistiska centralbyrån årligen en nationell folkhälsoenkät, H älsa på lika villkor. Undersökningen är en postenkät bestående av ett 70 tal frågor om bland annat hälsa, levnadsvanor, ekonomiska förhållanden, arbete, trygghet och sociala relationer. År 2005 skickades enkäten till 64000 personer i åldersgruppen 16 - 84 år och 63 procent svarade, 46 procent män och 54 procent kvinnor. För första gången ställdes en fråga om sexuell läggning i enkäten och homo- och bisexuella personers hälsa kunde därför jämföras med övriga befolkningens.

Totalt besvarades frågan av 29190 personer, 15784 kvinnor och 13406 män. Det interna bortfallet på frågan om sexuell läggning var 1028 personer och därutöver togs de som svarat att de var osäkra (230 personer) bort. Frågan Vilken är din sexuella läggning? hade svarsalternativen heterosexuell, heterosexuell med vissa homosexuella inslag, bisexuell, homosexuell med vissa he terosexuella inslag, homosexuell samt osäker på min sexuella läggning. Totalt var det 648 personer (drygt 2 procent) som inte definierade sig som enbart heterosexuella. Den största gruppen bland dem var heterosexuella med homosexuella inslag, 1,4 procent (304 personer), sedan följde bisexuella 0,8 procent ( 221 personer), homosexuella 0,7 procent ( 99 personer) och homosexuella med heterosexuella inslag 0,1 procent ( 24 personer).

Samtidigt med postenkäten genomfördes en internetbaserad hälsoenkät med samma frågor som nationella folkhälsoenkätens men också med specifikt riktade frågor till homo- och bisexuella och transpersoner (hbt) om trakasserier, diskriminering och öppenhet om sin sexuella läggning/könsidentitet. Enkäten fanns under två månader tillgänglig på webbplatser som besöks av målgruppen. Dessutom distribuerades enkäten via e-postlistor enligt "snöbollsmetoden". Totalt besvarades enkäten av 3388 personer, 37 procent kvinnor och 63 procent män.

3014 personer besvarade frågan om sexuell läggning. Dessutom uppgav 374 personer att de var transpersoner.

Den största gruppen, som inte identifierade sig som transpersoner var homosexuella (1 821 personer); därefter följde bisexuella (620 personer), homosexuella med heterosexuella inslag (331 personer) och heterosexuella med homosexuella inslag (122 personer).

På grund av för låg svarsfrekvens bland äldre i båda enkäterna, har svaren för åldersgruppen 65 - 84 inte analyserats. Nedan redovisas resultaten, som alla är statistiskt signifikanta, om inget annat anges.

\section{Resultaten}

\section{Självskattat allmänt hälsotillstånd}

Denna variabel bygger på frågan $\mathrm{H}$ ur bedömer du ditt allmänna hälsotillstånd? och har fem svarsalternativ, från mycket bra till mycket dåligt.

Den nationella folkhälsoenkäten visar att det var lika vanligt att ha ett mycket bra eller bra allmänt hälsotillstånd bland homo- och eller bisexuella män som bland män i övriga befolkningen. Däremot var det stora skillnader för kvinnorna, där 60 procent homo- och/eller bisexuella kvinnor uppgav att de hade en bra/ mycket bra allmän hälsa mot 72 procent bland kvinnor i den övriga befolkningen. Framför allt homo- och/eller bisexuella kvinnor i åldersgruppen 45 - 64 år och män i åldrarna 16 - 29 år uppgav att de hade sämre hälsa än dem i övriga befolkningen.

Av webbenkäten framgår att bisexuella män i alla åldersgrupper hade sämre hälsa än homosexuella, 10 procent bland bisexuella respektive fem procent bland homosexuella män hade dålig hälsa. För kvinnorna fanns inget entydigt mönster, utan 8 procent i båda grupper uppgav att de hade ett dåligt allmänt hälsotillstånd. Denna enkät visade också att det var vanligare med dålig hälsa bland bisexuella med mellanlång utbildning jämfört med lång utbildning, och dålig hälsa var vanligare bland dem som inte bodde i storstad jämfört med dem som levde i storstadsregionerna.

Bland transpersoner uppgav 67 procent att de hade bra hälsa och 12 procent att de hade dålig hälsa. I gruppen 16 - 29 år var andelen med dålig hälsa fyra gånger så stor som bland transpersoner 45 - 64 år. I den yngre åldersgruppen hade dessutom en större andel dålig hälsa jämfört med bisexuella personer, 23 respektive 6 procent.

\section{N edsatt psykisk hälsa}

Variabeln nedsatt psykisk hälsa mättes med GHQ 12, General Health Questionnaire, som är ett frågeinstrument med 12 frågor och mäter psykiska reaktioner på påfrestningar snarare än psykisk hälsa. Instrumentet är fokuserat på avbrott i den "normala" funktionen snarare än livslång karakteristika 
( M cD owell \& N ewell, 1996). På var och en av frågorna ges 0 poäng om den psykiska häl san var som vanligt eller bättre än vanligt och en poäng om psykiska hälsan var sämre eller mycket sämre än vanligt, maximalt kan alltså 12 poäng ges. B rytpunkten för nedsatt psykisk hälsa har här varit 3 poäng, vilket betyder att personer med 0 - 2 poäng hade god psykisk hälsa och de med 3 - 12 poäng hade nedsatt psykisk hälsa.

I folkhälsoenkäten uppgav 38 procent bland personer med homo- och/eller bisexuell läggning att de hade nedsatt psykiskt välbefinnande jämfört med 19 procent i övriga befolkningen. Skillnaden var mycket stor oavsett kön och ålder, förutom mellan homo- och bisexuella kvinnor och kvinnor i övriga befolkningen i åldrarna 30 - 44 år, där ingen skillnad förelåg.

A v webbenkäten framgår att bisexuella hade sämre psykiskt välbefinnande än homosexuella, 40 respektive 31 procent. Framför allt gällde detta bisexuella män i åldrarna 16 - 44 år och bisexuella kvinnor i åldrarna 16 - 29 år och 45 - 64 år. Ä ven här visade det sig att bland bisexuella med mellanlång utbildning fanns en större andel med nedsatt psykiskt välbefinnande än bland dem med lång utbildning, 46 respektive 34 procent.

Bland transpersoner uppgav 40 procent nedsatt psykiskt välbefinnande. Ô ver hälften av transpersoner i åldern $16-29$ år uppgav att de hade nedsatt psykiskt välbefinnande.

\section{Ä ngslan, oro eller ångest}

I folkhälsoenkäten ställdes frågan: $\mathrm{H}$ ar D u besvär av ängslan, oro eller ångest? Frågan har tre svarsalternativ. Här redovisas gruppen som har svarat ja, svåra besvär. Bland homo- och/eller bisexuella kvinnor var det mer än tre gånger så vanligt och bland män nästan dubbelt så vanligt att uppge svåra besvär av ängslan, oro eller ångest jämfört med övrig befolkning, 15 respektive 5 procent.

W ebbenkäten visade att bisexuella i större utsträckning än homosexuel la hade besvären, 20 respektive 13 procent. Den största andel en, 28 procent, fanns bland kvinnor i åldersgruppen 16 - 29 år.

Bland transpersoner uppgav 29 procent svåra besvär av ängslan, oro eller ångest, dubbelt så många som bland homosexuella. Störst var andelen i åldersgruppen 16 - 44 år.

A ndra variabler som mäter psykisk ohälsa i folkhälso- och webbenkäten är stress och sömnsvårigheter med fyra respektive tre svarsalternativ. Här redovisas de som upplevde sig mycket stressade och ett likartat mönster som i tidigare beskrivningar framträder: U ngdomar och kvinnor utmärkte sig särskilt vad gäller upplevelse av mycket stress. U nga homo- och/eller bisexuella män, 16 - 29 år, i folkhälsoenkäten uppgav mer än tre gånger så ofta att de kän de sig mycket stressade jämfört med övriga befolkningen, 7 respektive 2 procent. För unga kvinnor utgjorde andelarna 17 respektive 6 procent. Bland kvinnor i åldersgruppen 45 - 64 år var det 23 procent som kände sig mycket stressade mot 3 procent i övriga befolkningen.

I webbenkäten fanns inga skillnader i upplevelsen av mycket stress mellan homo- och bisexuella personer, 7 respektive 8 procent. Bland unga personer framträdde dock skillnader, med större andelar stress för bisexuella ungdomar. Bland transpersoner uppgav 11 procent att de kände sig mycket stressade.
Svåra sömnsvårigheter var enligt folkhälsoenkäten dubbelt så vanligt bland homo- och/ eller bisexuella personer jämfört med övriga befolkningen, 12 respektive 6 procent. Skillnaden var störst bland kvinnor i åldersgruppen 45 - 64 år, där 21 procent bland homo- och/ eller bisexuella kvinnor upplevde svåra besvär jämfört med 9 procent i övrig befolkning.

I webbenkäten fanns tendenser

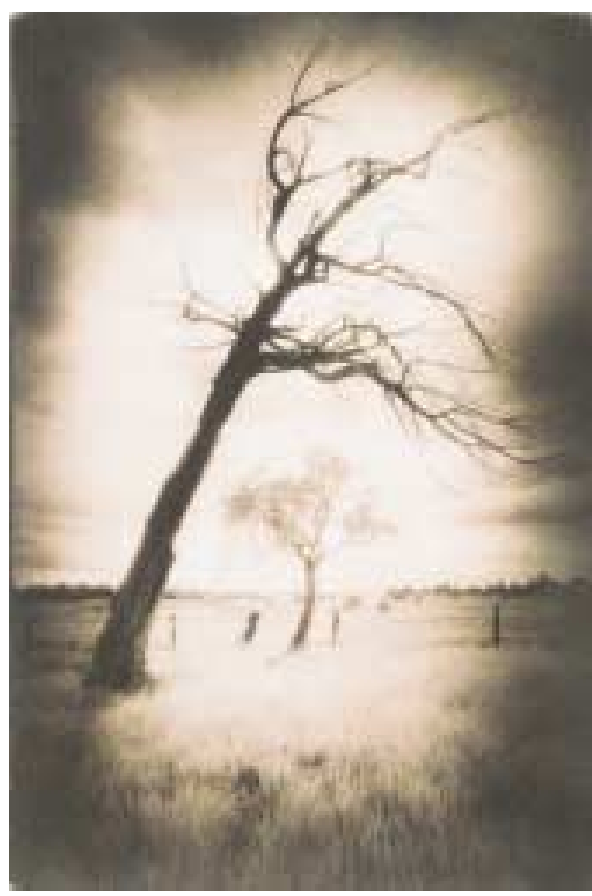

till skillnader mellan homo- och bisexuella kvinnor och män, där 10 respektive 13 procent uppgav svåra sömnsvårigheter. Transpersoner uppgav i större utsträckning svåra sömnsvårigheter, 17 procent.

\section{Självmordstankar och självmordsförsök}

Dessa variabler bygger på frågorna: $\mathrm{H}$ ar du någon gång kommit i den situationen att du allvarligt övervägt att ta ditt liv? och $\mathrm{H}$ ar du någon gång försökt ta Ditt liv? Svarsalternativen var $\mathrm{N}$ ej, Ja, en gång och Ja, flera gånger. D e som svarade att de övervägt eller försökt ta sitt liv en eller flera gånger bedömdes i analysen ha haft självmordstankar respektive försökt ta sitt liv.

\section{Självmordstankar}

I folkhälsoenkäten uppgav dubbelt så många bland homo- och/ eller bisexuella att de en eller flera gånger övervägt att ta sitt liv än i övriga befolkningen, 29 respektive 14 procent. Självmordstankar var vanligare bland såväl homo- och/eller bisexuella kvinnor som män. I åldersgruppen 16 - 29 år var det 53 procent bland kvinnorna och 47 procent bland män som hade haft självmordstankar jämfört med 21 respektive 14 procent i övriga befolkningen.

I webbenkäten fannsinga skillnader mellan homo- och bisexuella personer, 45 respektive 45 procent. Bland homosexuella kvinnor i åldersgruppen 45 - 64 år hade en större andel haft självmordstankar jämfört med bisexuella, 46 procent respektive 30 procent (ej signifikant). H omosexuella med kort utbildning hade i större utsträckning övervägt att ta sitt liv jämfört med homosexuella med lång utbildning, 56 procent respektive 41 procent.

Bland tran spersoner hade hälften någon gång tänkt ta sitt liv och i åldersgruppen 16 - 29 år var det 65 procent. 


\section{Självmordsförsök}

Enligt folkhälsoenkäten var det mer än dubbelt så stor andel homo- och/eller bisexuella personer som uppgav att de en eller flera gånger försökt ta sitt liv jämfört med övriga befolkningen, 12 respektive 5 procent. Framför allt var det homo- och/ eller bisexuella kvinnor i den yngsta och i den äldsta åldersgruppen som försökt ta sitt liv. Det var 21 procent i gruppen 16 - 29 år respektive 11 procent bland 45 - 64-åringar, vilket kan jämföras med 8 respektive 5 procent i övriga befolkningen. Se figur 1 .

Figur 1. Andel män och kvinnor som någon gång försökt ta sitt liv, fördelat efter sexuell läggning och ålder ( $n=29058$ )
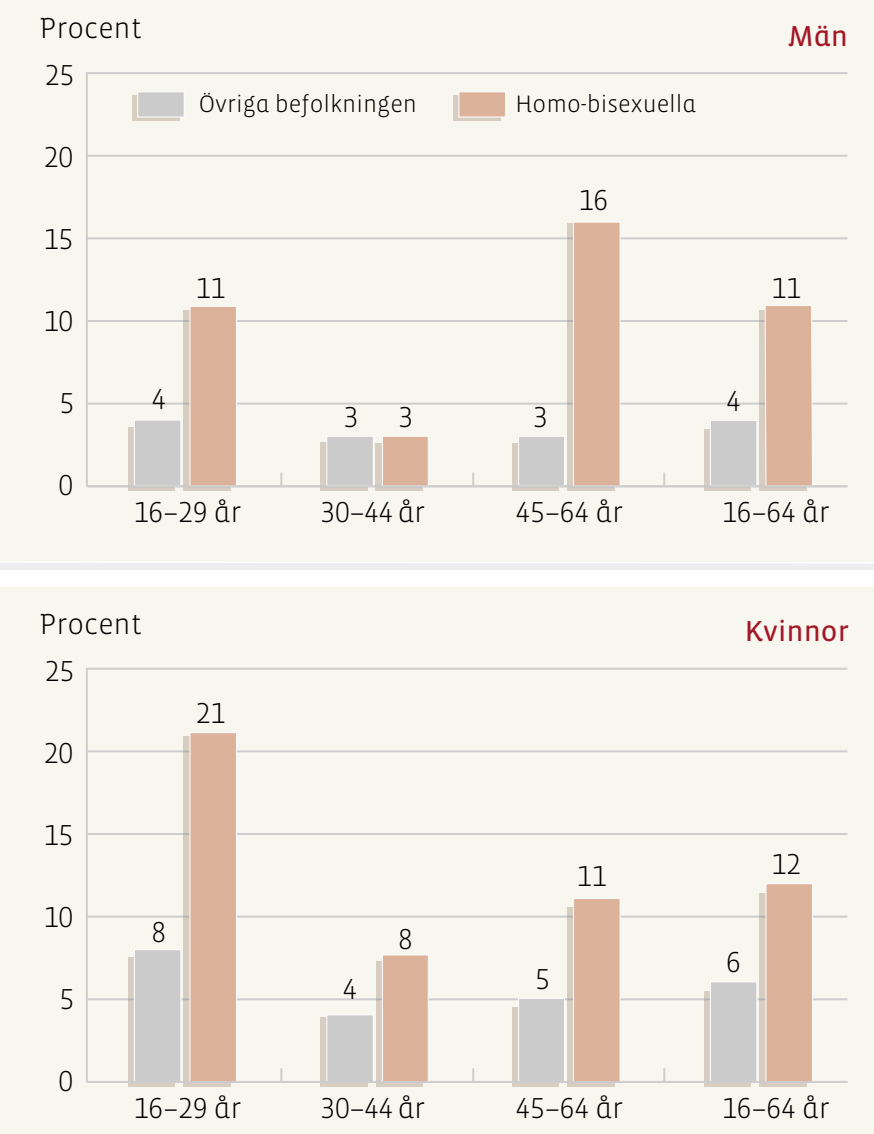

Källa: Nationella folkhälsoenkäten, 2005, Statens folkhälsoinstitut

Enligt webbenkäten var det nästan lika vanligt bland homooch bisexuella personer att någon gång försökt ta sitt liv, 16 respektive 18 procent. Bland bisexuella tenderade självmordsförsök att vara vanligast i åldrarna 16 - 44 år medan självmordsförsök bland homosexuella fördel ade sig mer jämt över åldrarna. Bland såväl homo- som bisexuella fanns tydliga samband med utbildningslängd: Bland dem med kort utbildning hade 29 respektive 27 procent gjort ett eller flera självmordsförsök jämfört med 9 respektive 14 procent bland dem med lång utbildning.

Bland homosexuella som var födda utrikes var andelen som försökt ta sitt liv nästan dubbelt så stor jämfört med dem som var födda i Sverige, 26 respektive 14 procent. För bisexuella kunde däremot inte denna skillnad konstateras.
Bland transpersoner hade 21 procent någon gång försökt ta sitt liv och vanligast var det i åldersgruppen 16 - 44 år, där 27 procent hade gjort ett eller flera självmordsförsök. Se fig. 2.

Figur 2. Andel transpersoner som någon gång försökt ta sitt liv, fördelat efter ålder ( $n=292)$

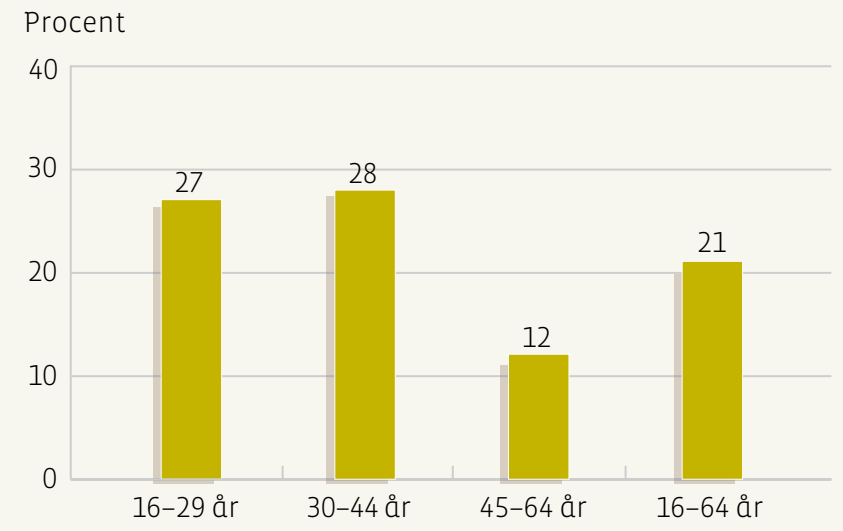

Källa: Webbenkäten, 2005, Statens folkhälsoinstitut

Ä ven i gruppen transpersoner hade utbildningsbakgrund samband med självmordsförsök: bland dem med kort utbildning uppgav 35 procent och bland dem som hade lång utbildning 13 procent att de hade försökt ta sitt liv ett eller flera gånger.

A ndra viktiga determinanter som har samband med psykisk hälsa som mättes i både nationella folkhälsoenkäten och i webbenkäten var tillit till andra människor, tillgång till emotionellt stöd, tillgång till praktiskt stöd och deltagande i sociala aktiviteter. Ä ven utsatthet $i$ form av rädsla för överfall, rån eller annat ofredande, utsatthet för hot, våld och trakasserier och utsatthet för kränkande behandling/ bemötande mättes $i$ båda enkäter.

I webbenkäten ställdes därutöver frågor om rädsla för våld eller trakasserier på grund av sexuell läggning eller könsidentitet/ könsuttryck och utsatthet för diskriminering.

Vad gäller dessa determinanter i folkhälsoenkäten, var homooch/eller bisexuella män och kvinnor mer i avsaknad av tillit till andra människor, hade mindre av emotionellt och praktiskt stöd och deltog i mindre utsträckning i sociala aktiviteter än övriga befolkningen. Såväl rädsla för överfall, rån eller ofredande som utsatthet för hot, våld och trakasserier och utsatthet för kränkande behandling/bemötan de var betydligt vanligare bland homo- och/eller bisexuella män och kvinnor än i övriga befolkningen. Enligt W ebbenkäten var en större andel homosexuella rädda för våld eller trakasserier och var mer utsatta för hot, våld och trakasserier än bisexuella. A tt ha blivit utsatt för diskriminering på grund av sexuell läggning någon gång under livet var ungefär lika vanligt bland homosexuella personer som bland bisexuella, 21 respektive 19 procent.

\section{Konklusion}

Folkhälsoenkätens resultat visar att den psykiska hälsan bland homo- och/eller bisexuella är betydligt sämre än bland dem i 
övriga befolkningen. Speciellt allvarligt är de stora andelarna med självmordstankar och själmordsförsök i gruppen. D essa resultat är i linje med tidigare undersökningar, där man i samma studie har jämfört självmordstankar och självmordsförsök bland homo- och bisexuella ungdomar och unga vuxna och jämfört med heterosexuella unga (D uR ant et al., 1998; Faulkner \& Cranston, 1998; Fergusson et al., 1999; $G$ arofalo et al., 1998; Remafedi et al., 1998; W ichstrom \& H egna, 2003).

M otsvarande mönster med den stora andelen av självmordstankar och självmordsförsök bland homo- och bisexuella jämfört med heterosexuella gäller också för vuxna (Bagley \& Tremblay, 1997; C ochran \& M ays, 2000; Gilman et al., 2001; Herrell et al., 1999; Jorm et al., 2002). Då det inte finns belägg för att hälsoproblem bland homo- och bisexuella har samband med genetiska eller biologiska faktorer är det rimligt att söka förklaringar i det omgivande samhället, såsom majoritetens skepsis till och negativa särbehandling av icke-heterosexuella samlevnadsformer, men också hot, övergrepp, social utstötning och diskriminering. Ett sätt att se problemet är att majoritetssamhället med sin heteronorm framkallar stress bland sina minoriteter. M eyer (2003) relaterar i sin översiktsartikel den ökade förekomsten av psykisk ohälsa - inklusive självmordstankar och självmordsförsök - till minoritetsstress framkallad genom bland annat stigmatisering och diskriminering. I såväl en svensk som en amerikansk befolkningsstudie rapporterar homo- och bisexuella oftare än heterosexuella diskriminering framför allt $\mathrm{i}$ arbetslivet, men även i vardagl iga kontakter (Bildt \& A rbetslivsinstitutet, 2004; M ays \& C ochran, 2001). D et finns en växande evidens för att upplevd diskriminering, såsom den påvisas i folkhälsoenkäten bland homo- och/eller bisexuella, har samband med psykisk ohälsa (Clark et al., 1999; Kessler et al., 1999). I syfte att bidra till en minskning av samhällets heteronormativitet och att förbättra hälsan för hbt-personer har Statens folkhälsoinstitut överlämnat åtgärdsförslag till regeringen. D essa förslag och hela undersökningen finns fritt tillgängliga som pdf-filer på FHI:s hemsida www.fhi.se. R apporten H älsa på lika villkor? $\mathrm{H}$ älsa och livsvillkor bland hbt-personer, som resultatdelen av denna artikel bygger på, kan även beställas till självkostnadspris (Roth et al., 2006).

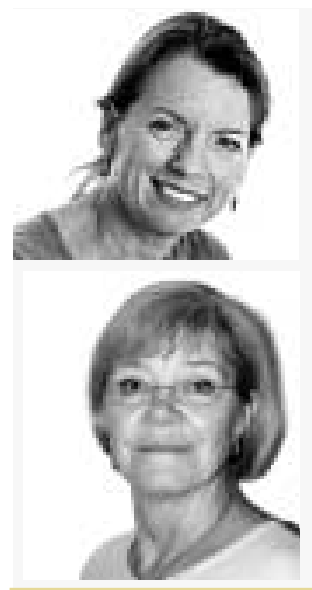

R egina W inzer är medicine magister $i$ folkhälsovetenskap och socionom. H on är anställd vid Statens folkhälsoinstitut och arbetar bland annat med frågor om unga vuxnas psykiska hälsa. U nder år 2004 - 2005 var hon projektledare för ett regeringsuppdrag att utreda och analysera hälsosituationen för homosexuel la, bisexuella och transpersoner ( $\mathrm{hbt}$ ) samt föreslå åtgärder.

G unnel B oström är utredningsledare på Statens folkhälsoinstitut och ansvarig för den nationella folkhäl soenkäten i Sverige. U ndersökningen görs varje år sedan år 2004 och från och med år 2005 finns frågor om självmordstankar och självmordsförsök med i undersökningen. Gunnel är också en av författarna till rapporten som här refereras.

\section{Referenser}

Bagley, C., \& Tremblay, P. (1997). Suicidal behaviors in homosexual and bisexual males. Crisis, 18(1), 24-34.

Bailey, J. M . (1999). H omosexuality and mental illness. A rch G en Psychiatry, 56(10), 883-884

Bildt, C., \& A rbetslivsinstitutet. (2004). R edovisning av regeringsuppdraget att beforska homo- och bisexuellas arbetsvillkor. Stockholm: A rbetslivsinstitutet.

Clark, R., A nderson, N. B., Clark, V. R., \& Williams, D. R. (1999). R acism as a stressor for A frican A mericans. A biopsychosocial model. A m Psychol, 54(10), 805-816.

Cochran, S. D., \& M ays, V. M . (2000). Lifetime prevalence of suicide symptoms and affective disorders among men reporting same-sex sexual partners: results from N H A N E S III. A m J Public H ealth, 90(4), 573-578.

Cochran, S. D., M ays, V. M ., \& Sullivan, J. G . (2003). Prevalence of mental disorders, psychological distress, and mental health services use among lesbian, gay, and bisexual adults in the U nited States. J Consult C lin Psychol, 71(1), 53-61.

DuRant, R. H., Krowchuk, D. P., \& Sinal, S. H . (1998). Victimization, use of violence, and drug use at school among male adolescents who engage in samesex sexual behavior. J Pediatr, 133(1), 113-118.

Faulkner, A . H ., \& C ranston, K. (1998). C orrelates of same-sex sexual behavior in a random sample of Massachusetts high school students. A m J Public H ealth, 88(2), 262-266.

Fergusson, D. M ., H orwood, L. J., \& Beautrais, A . L. (1999). Is sexual orientation related to mental health problems and suicidality in young people? A rch G en Psychiatry, 56(10), 876-880.

Garofalo, R., W olf, R. C., Kessel, S., Palfrey, S. J., \& DuRant, R. H. (1998). T he association between health risk behaviors and sexual orientation among a schoolbased sample of adolescents. Pediatrics, 101(5), 895-902.

Gilman, S. E., Cochran, S. D., M ays, V. M., H ughes, M., O strow, D., \& Kessler, R. C. (2001). R isk of psychiatric disorders among individuals reporting samesex sexual partners in the $\mathbf{N}$ ational C omor-bidity Survey. A $m$ J Public $\mathrm{H}$ ealth, 91(6), 933-939.

H egna, K., Kristiansen, H . W., \& M oseng, B. U . (1999). Levekår og livskvalitet blant lesbiske kvinner og homofile menn. $O$ slo: $N$ ova.

H errell, R., G oldberg, J., True, W. R., Ramakrish-nan, V., Lyons, M ., Eisen, S., et al. (1999). Sexual orientation and suicidality: a co-twin control study in adult men. A rch G en Psychiatry, 56(10), 867-874.

Jorm, A . F., Korten, A . E., Rodgers, B., Jacomb, P. A ., \& C hristensen, H. (2002). Sexual orientation and mental health: results from a community survey of young and middle-aged adults. Br J Psychiatry, 180, 423-427.

Kessler, R. C., M ickelson, K. D., \& Williams, D. R. (1999). T he prevalence, distribution, and mental health correlates of perceived discrimination in the U nited States. J H ealth Soc Behav, 40(3), 208-230.

M ays, V. M ., \& Cochran, S. D. (2001). M ental health correlates of perceived discrimination among lesbian, gay, and bisexual adults in the $U$ nited States. A m J Public H ealth, 91(11), 1869-1876.

M cD owell, I., \& N ewell, C. (1996). M easuring health: a guide to rating scales and questionnaires (2. ed.). N ew York: Oxford U niv. Press.

M eyer, I. H . (2003). Prejudice, social stress, and mental health in lesbian, gay, and bisexual populations: conceptual issues and research evidence. Psychol Bull, 129(5), 674-697.

Remafedi, G., French, S., Story, M., Resnick, M. D., \& Blum, R. (1998). T he relationship between suicide risk and sexual orientation: results of a populationbased study. A m J Public H ealth, 88(1), 57-60.

Roth, N ., N ykvist, K., Boström, G ., \& Statens folkhälsoinstitut. (2006). H älsa på lika villkor? hälsa och livsvillkor bland H B T-personer. Stockholm: Statens folkhälsoinstitut.

Sandfort, T. G . de G raaf, R. Bijl, R. V. \& Schna-bel, P. (2001). Same-sex sexual behavior and psychiatric disorders: findings from the $\mathrm{N}$ etherlands $M$ ental $H$ ealth Survey and Incidence Study (N EM ESIS). A rch G en Psychiatry, 58(1), 85-91.

W ichstrom, L., \& H egna, K. (2003). Sexual orientation and suicide attempt: a longitudinal study of the general $\mathrm{N}$ orwegian adolescent population. J A bnorm Psychol, 112(1), 144-151. 